\title{
Adverse outcomes in SAR-CoV-2 (COVID-19) and SARS virus re- lated pregnancies with probable vertical transmission
}

\author{
Gulam Bahadur ${ }^{1,2}$, Roy Homburg ${ }^{2}$, Wai Yoong ${ }^{1}$, Cheentan Singh ${ }^{3}$, Mamta Bhat ${ }^{4}$, Phalguni Kotabagi ${ }^{1}$, Santanu \\ Acharya $^{4}$, Judith Huirne ${ }^{5}$, Pablo Alexis Doreski ${ }^{6}$, Mariusz Łukaszuk7, Asif Muneer ${ }^{8}$
}

\author{
${ }^{1}$ Reproductive Medicine Unit, Obstetrics \& Gynaecology Department, North Middlesex University Hospitals \\ Trust, London UK. \\ ${ }^{2}$ Homerton Fertility Centre, Homerton University Hospital. London, UK. \\ ${ }^{3}$ Neonatal and Peadiatric Unit, North Middlesex University London. London, UK. \\ ${ }^{4}$ Ayrshire Fertility Unit, University Hospital Crosshouse, Kilmarnock, Scotland. \\ ${ }^{5}$ University Medical Centers Amsterdam, Research Institute Reproduction and Development. Amsterdam, The \\ Netherlands. \\ ${ }^{6}$ Fundacion Respirar, Buenos Aires. Argentina \\ ${ }^{7}$ Nowe Orlowo Medical Center, Gdynia, Poland \\ ${ }^{8}$ University College London Hospital NIHR Biomedical Research Centre. London, UK.
}

\begin{abstract}
The global severe acute respiratory syndrome-related coronavirus SARS-CoV-2 (COVID-19) pandemic has had an unprecedented impact on all aspects of daily life and healthcare. Information on the infection risks for pregnant women and their offspring have so far been limited to small case series, until a large UK report on 427 SARSCoV-2 infected pregnant women was published. Previous SARS epidemic experiences were drawn upon. Diagnostic use of real time polymerase chain reaction (RT-PCR) and IgG and IgM antibody tests are fraught with concerns of non-validation and false negative results, as are sampling methodologies. Virtually no information on controls accompany these reports. Infection of the mother and baby has serious implications for obstetric and neonatal care. Information on early and late stage pregnancy infection and the relationship to severity of infection on fetal development is both useful and clearly warranted. An increasing number of reports centre around mildly infected women showing no evidence of fetal infection while a few reports suggesting vertical transmission require further validation. Vertical transmission from mother to baby however small would have profound health implications for obstetric and neonatal care and fetal abnormalities. Some data suggesting intrapartum vertical transmission from mother to baby cannot be dismissed given the lack of controls and limitations of diagnostic viral tests. This analysis covers some key early reports addressing pregnancy outcomes following SARS-CoV-2 infection.
\end{abstract}

Keywords: COVID-19, SARS-CoV-2, pregnancy, risks, vertical transmission

\section{Background}

The global SARS-CoV-2 (COVID-19) pandemic has focussed unprecedented public health priorities and suspended all fertility treatment to prevent the spread of infection. Previous SARS pregnancies were associated with a high incidence of spontaneous preterm delivery, miscarriage, and intrauterine growth restriction, but provided no evidence of perinatal SARS infection amongst the infants who were born (Wong et al., 2004). The data collections for the various periods were heterogeneous with globally localised experiences such as USA. Even with the current SARS-CoV-2 pandemic, there is no centralised linked data collection for pregnancy and neonatal outcomes. In the UK this role should be covered by the Office of National Statistics (ONS, 2020), and by an independent research group UK Obstetric Surveillance System (UKOSS). Submitting data to professional societies or individual research groups is voluntary and prone to bias especially if permission from hospitals is restricted with small numbers, potentially breaching privacy, or withheld to prevent unnecessary media attention. Of particular interest to clinicians is it vertical transmission from mother to baby occurs.

Angiotensin-converting enzyme 2 (ACE2) is the receptor for SARS-CoV-2, and has a central role in human infection and ongoing transmission. ACE2 is highly expressed in maternal-fetal interface cells which includes stromal cells and perivascular cells of decidua and cytotrophoblast as well as syncytiotrophoblast within the placenta. Therefore, SARS-CoV-2 associated vertical transmission and the placenta dysfunction/abortion need to be investigated in clinical practice (Li et al., 2020). Preliminary unverified reports state that embryos harbouring SARS-CoV-2 receptors ACE2 and BSG (CD147), the serine protease TMPRSS2 and the endosomal protease CTSL also raise concerns about the possible hazard to the developing embryos and hence early pregnancy loss or complications (Colaco et al., 2020). ACE2 and TMPRSS2 expression in oocytes, ovarian tissue and testicular tissue serve as possible targets for SARS-CoV-2 virus (Stanley et al.,2020). Therefore, IVF procedures present several levels of complexities over and above the known risks of surgical procedures, multiple births and OHSS. In contrast, IUI in the SARS-CoV-2 post pandemic provides exceptionally low risk, low intrusive benefits and a logistical fertility treatment pathway (Bahadur et al., 2020).

We highlight the key pregnancy related reports appearing up to $26 / 05 / 2020$.

\section{Possible vertical transmission}

From previous virology reports, the rate and risk of viral transmission appears to increase with advancing fetal gestation. Once viruses cross the placental barrier, depending on gestation, they can cause serious fetal effects including birth defects, abnormalities of growth and development, neurological injuries, miscarriage, fetal death, preterm delivery and neonatal complications (Silasi et al., 2015; Schwartz \& Schwartz, 2020). Vertical transmission mechanisms are poorly understood (Schwartz \& Schwartz, 2020), and could possibly be through a maternal hema- 
togenous route via the maternal-fetal interface. Viruses circulating in the maternal bloodstream enter the placenta from uterine arteries, circulate in the intervillous space, and can pass to the fetus through the chorionic villous tree where they eventually enter the fetal circulation (Schwartz \& Schwartz, 2020).

Various reports exist for pregnancy and neonatal infections. Very early cases of neonatal infections provide significant information on the maternal and neonatal interrelationship. One study found that three neonates tested positive for SARS-CoV-2 and one neonate was infected with SARS-CoV-2 36h following delivery (Yu et al., 2020). One neonate which was 16 hours post-delivery was found to be positive using real-time polymerase chain reaction (RTPCR) but the immunoglobulin IgM and IgG for SARS-CoV-2 were both negative, suggesting a possible vertical transmission. Interestingly, there were no maternal antibodies detected until after delivery and all three babies had positive RT-PCR on day 2 (Alzamora et al., 2020). The report does not include whether there was an antibody response in the neonate. Three neonates had elevated SARS-CoV-2 IgG and IgM levels but the RT-PCR test was negative. Two new-born babies delivered by Caesarean section tested positive for SARS-CoV-2 by RT-PCR assay which suggests vertical or peripartum transmission of SARS-CoV-2 (Parazzini et al., 2020). The earliest single case report of a 2-hour newborn with elevated SARS-CoV-2 IgM antibodies to be born to an infected mother suggests that the neonate was infected in utero and points to possible vertical transmission (Dong et al., 2020). The large macromolecular IgM unlike IgG is unlikely to cross the placenta from the maternal compartment to the fetus (Zeng et al., 2020). RT-PCR testing of the patient's vaginal secretions and later on the breast milk were negative. Potentially, the infant could have been exposed for 23 days from the time of the mother's diagnosis of SARS-CoV-2 to delivery. IgM antibodies do not appear until 3 to 7 days post infection and are not transferred to the fetus via the placenta; therefore, infection was least likely during delivery. The infant's repeatedly negative RT-PCR test results were difficult to explain and such tests are not always positive with infection (Dong et al., 2020). Caution should still be exercised given the sensitivity and specificity of the IgM assay was $70.2 \%$ and $96.2 \%$ respectively. SARS-CoV-2 infection positive vertical transmission was described in one of the seven $(14.3 \%)$ neonates tested within the first 24-36 hours of life (Hu et al., 2020). The data suggested vertical transmission of SARS-CoV-2 infection from mothers during the last few days of pregnancy was possible but urge caution in the interpretation. Perinatal SARSCoV-2 infection and vertical transmission is also hypothesized (Chen et al., 2020a; Zeng et al., 2020a). An early-onset neonatal infection with elevated IgM antibody to the virus could not confirm intrauterine vertical transmission of SARS-CoV-2 (Schwartz \& Schwartz, 2020). In a COVID-19 infected neonate case report showed positive RT-PCR assay 36 hours after birth, but had negative cord blood and placenta. There was insufficient information to establish vertical transmission from the mother to the child (Wong et al., 2020). RT-PCR was positive in the amniotic fluid and throat swab at 24 hours, for the baby born at 32 weeks gestation to the mother with symptomatic COVID which strongly raises the possibility of vertical transmission (Zamaniyan et al., 2020). Transplacental vertical transmission could not be excluded in 5 out of 70 cases $(7.1 \%$ of neonates) (Fornari, 2020).

Newer cases for vertical transmission from mother to baby are recorded. In the first report of its type, 3/11 placental swabs tested positive for SARSCoV-2 RNA although the babies remained negative
(Penfield et al., 2020). Despite the limitations of reporting a single case without RT-PCR of amniotic fluid or placenta one newborn did have elevated SARS-CoV-2 IgM antibodies to a mother infected with COVID-19 (Dong et al., 2020). RT-PCR on amniotic fluid and infant tested positive for COVID-19 infection (Zamaniyan et al., 2020).

\section{Placental pathology after viral infection}

If antepartum vertical transmission from mother to baby is to be confirmed then ideally SARS-CoV-2 virus detection by electron micrography to the placenta, cord blood and amniotic fluid should occur. The placenta is an immuneprivileged site and viral detection is complex because of the various compartments. Confirmation of viral damage to placenta is another line of evidence or is isolating and incubating tissue to release the virus to check for infectivity. The challenges of identifying SARS-CoV-2 virus were highlighted in infected endothelial cells using electron microscopic and where ribosomes appeared to be identified rather than the spikes on coronavirus particles (Goldsmith et al., 2020).

Compared to historical controls, placenta from 16 patients infected with SARS-CoV-2 showed decidual arteriopathy and maternal vascular malperfusion (Shanes et al., 2020). The SARS-CoV-2 infected placenta however, showed no significant increase in acute or chronic inflammatory pathology. Third trimester placentas showed at least one feature of maternal vascular malperfusion (MVM), particularly abnormal or injured maternal vessels, and intervillous thrombi. The placenta of one second trimester fetal demise had villous edema and a retroplacental hematoma (Shanes et al., 2020). One infected patient was hypertensive despite the association of MVM with hypertensive disorders and preeclampsia. These changes may reflect a systemic inflammatory or hypercoagulable state influencing placental physiology. Placental injury affects intervillous space oxygenation which in turn is associated with adverse perinatal outcomes (Shanes et al., 2020). None of the SARS-CoV-2 associated placentas were tested for viral RNA or protein. The abnormal maternal circulation and an increased incidence of chorangiosis gives a mechanistic clue into the infection related changes.

Similar morphological and anatomic-pathological changes were noted during Zika virus infections. These included; increased stromal cellularity, villitis, calcification, maternal vascular malperfusion, placental hypoplasia, and maternal-fetal haemorrhage (intervillous thrombi). Different regions of the placenta such as the umbilical cord, amniotic membrane, chorionic plate, chorionic villus, and basal plate from pregnant women can be infected with the Zika virus. However, the collection and storage of the placenta were vital in the successful detection of Zika (Venceslau et al., 2020). Following viral infection, endometrial microbiota changes alter endometrial receptivity, giving higher miscarriage rates and poor implantation rates following IVF treatments (Moreno et al., 2016).

Increased endometrial expression of ACE2 with gonadotropin-induced changes in animal models need further evaluation in human fertility treatments (Pereira et al., 2009). Equally, the increased expression of ACE2 in the glandular epithelium of mid-to-late secretory phase of the menstrual cycle (Vaz-Silva et al., 2009) raises the risk for localised SARS-CoV-2 infections.

Two reports make a compelling case for vertical transmis- sion showing SARS-CoV-2 viral particle and or damage to the placenta (Hosier et al., 2020, Kirtsman et al., 2020). Electron microscopy of SARS-CoV-2 particles within the chorionic villi and in different placental cell types, cytotrophoblast, syncytiotrophoblast and fibroblast showed SARS-CoV-2 was found mainly in the syncytiotrophoblast cells at the maternal-fetal interface of the placenta in a 
second trimester of pregnancy (Hosier et al., 2020). This is probably the first case of transplacental transmission and reinforces the concern and risk with infectious disease in neonates. Congenital SARS-CoV-2 infection, with virus present in a neonate's nasopharynx at the time of birth suggest vertical transmission may have occurred (Kirtsman et al., 2020). The placental photomicrographs showed broad zones of cellular infiltrates with infiltration of the intervillous space by chronic inflammatory cells. The chorionic villi showed extensive early necrosis of the syncytiotrophoblast layer and there was early infarction, with extensive smudginess and early fragmentation of the syncytiotrophoblast nuclei (Kirtsman et al., 2020).

\section{The evidence for no vertical transmission}

Most cases exclude vertical transmission. No evidence of vertical transmission was identified in a cohort of 10 babies born to 9 mothers, all having negative throat swabs for SARS-Cov-2 using RT-PCR taken between day 1 to day 9 (Zhu et al., 2020). Furthermore, no vertical transmission of COVID-19 was found in the third trimester of pregnancy amongst neonates delivered vaginally (Khan et al., 2020; Xiong et al., 2020). In 31 COVID-19 infected pregnant mothers, no COVID-19 infection was detected in neonates or in the placenta. Two mothers died from COVID-19-related respiratory complications postpartum but there was no evidence for intrauterine transmission of COVID-19 from infected pregnant women to the fetus. An increased risk for severe respiratory complications for infected mothers is reported (Karimi-Zarchi et al., 2020). Equally, an analysis from 55 COVID-19 infected pregnant women and 46 neonates suggests that there is no definite evidence of vertical transmission (Dashraath et al., 2020). In women diagnosed with SARS-CoV-2 in the 3rd trimester, no definitive evidence of intrauterine vertical transmission during pregnancy was demonstrated, whilst acknowledging transmission in the 1st and 2nd trimester remains unknown and that high-quality analyses would be required to rule out vertical transmission (Cheruiyot et al., 2020).

It may not be surprising that vertical transmission is not found in mildly infected pregnant women or if there is a very short duration of maternal infection exposure to the early stage of fetal development. SARS-CoV-2 virus crossing the placental barrier needs to be confirmed especially in severely infected mothers (Kimberlin \& Stagno, 2020). Interpreting negative RT-PCR along with numerous sampling methods has severe limitations especially given there is a latent incubation period for the virus. In SARSCoV-2 infected adults, most individuals tested negative and only became positive after repeated testing on days which followed (Kelly et al., 2020). The period from symptoms occurring to RT-PCR test becoming positive presents high risk for spreading the virus. We therefore do not have a full understanding as to when the optimal sample should be taken. Researchers are suggesting samples taken at the maternal and neonatal interphase should be retained for later research, presumably when testing improves.

\section{UK experience on SARS-Cov-2 infection in pregnant women}

In the UK, UKOSS, reported on 427 pregnant women diagnosed with SARS-CoV-2 the pregnant women were no more likely than non-pregnant women to become severely ill with SARS-Cov-2 (Knight et al., 2020). However, there was a greater likelihood of becoming severely ill in their 3rd trimester of pregnancy. Co-morbidities were deemed to be important factors; overweight, older pregnant women or pregnant women with pre-existing comorbidities, such as hypertension and diabetes, were more likely to be admitted to hospital with SARS-Cov-2. Black and ethnic minority pregnant women were also more likely to be admitted to hospital with SARS-Cov-2 infection. Of these, 1 in 5 babies were born prematurely and required admission to a neonatal unit, fewer than 20 babies were born very premature. One in 20 babies born tested positive for SARS-Cov-2, but only half of these babies had a positive test immediately after birth. Whilst this study is suggesting low transmission of infection from mother to baby, the science and limitations of the diagnostic tests where both validation and uncertainty measurements remain absent, the true size of infected neonates remains to be seen (Knight et al., 2020). UKOSS revealed 247 women (58\%) gave birth or had a pregnancy loss; 180 (73\%) gave birth at term, 40 (9\%) hospitalised women required respiratory support. Of the 12 infants (5\%) testing positive for SARS-CoV-2 RNA, 6 infants were positive within the first 12 hours after birth. Overall, 5 women admitted for SARS-CoV-2 died, a case fatality of $1.2 \%$ (95\% CI $0.4-2.7 \%$ ) and a SARS-CoV-2-associated maternal mortality rate of 5.6 (95\%CI 1.8-13.1) per 100,000 maternities (Knight et al., 2020). In contrast, the maternal mortality rate from $\mathrm{H} 1 \mathrm{~N} 1$ influenza was 1.6 per 100,000 pregnant women (Yates et al., 2010), although caution should be exercised in comparing heterogeneous and small sized cohorts. There remain major disparities in data collection from UK research interest groups and the main UK government ONS body gathering data. A Freedom of information request from the ONS revealed only 1 maternal death (ONS, 2020), whereas 5 deaths were reported through voluntary submission to UKOSS research group. This data would not capture the general population unreported deaths. Data collection in future pandemics will need better joined up structures and rules.

\section{Other pregnancy experience}

In one systematic review of mothers infected with a variety of coronavirus infections that have caused epidemics in the recent past, 19 studies were included with 79 women: 41 pregnancies (51.9\%) affected by COVID-19, 12 $(15.2 \%)$ by MERS, and $26(32.9 \%)$ by SARS. For all CoV infections, the rates of adverse effects were as follows: miscarriage $(39.1 \%)$, preterm birth $<37$ weeks $(24.3 \%)$, premature pre-labour rupture of membranes (20.7\%), preeclampsia $(16.2 \%)$, and fetal growth restriction $(11.7 \%)$; $84 \%$ were delivered by Caesarean section; the rate of perinatal death was $11.1 \%$ and $57.2 \%$ for newborns admitted to the neonatal ICU. When focusing on COVID-19, the commonest adverse pregnancy outcome was premature birth $<37$ weeks, which occurred in $41.1 \%$ of cases, whilst the rate of perinatal death was quoted as $7 \%$ but none of the new-borns had vertical transmission (Di Mascio et al., 2020). Fetal distress, premature labour, respiratory distress, thrombocytopenia accompanied by abnormal liver function and possibly death may be associated with SARSCOV-2 infection (Zhu et al., 2020).

In another systematic review of 108 COVID-19 infected pregnancies, severe maternal morbidity and perinatal deaths were reported, whilst COVID-19 vertical transmission could not be excluded (Zaigham \& Andersson, 2020). Most cases were in the 3rd trimester and associated with fever $(68 \%)$, coughing (34\%), lymphocytopenia (59\%) with elevated C-reactive protein (70\%) and $91 \%$ were delivered by caesarean section. There were no maternal deaths, but 3 maternal ICU admissions were required. One intrauterine death and one neonatal death was recorded. In neonatal blood sera from mothers infected with SARS-CoV-2, IgG concentrations in 5 infants were elevated. IgG usually transfers across the placenta from mother to fetus at the end of the 2nd trimester and reaches peak levels by the time of birth. On the 
other hand, IgM, was detected in 2 infants. IgM is not usually transferred from mother to fetus due to the large macromolecular structure (Zeng et al., 2020b). The placenta of 2 SARS-CoV infected women in the third trimester of pregnancy had abnormal weights and pathology.

One experience suggests that there is no evidence of higher maternal or fetal risks and that pregnant women infected with SARS-CoV-2 would have similar outcomes to those non-infected pregnant women (Monteleone et al., 2020). From, 18 studies comprising 114 mildly infected, 3rd trimester pregnant women, the fetal and neonatal outcomes appeared normal and without evidence of intrauterine vertical transmission (Yang et al., 2020). In contrast, the first peer reviewed report detailed the death of a 27-year-old pregnant woman (Karami et al., 2020). A second trimester miscarriage case related to SARS-CoV-2 placental infection was reported (Baud et al., 2020). Miscarriage or fetal growth restriction was observed in $40 \%$ of maternal infections with MERS and SARS viruses (Favre et al., 2020; Wong et al., 2004) and there are insufficient cases to determine with confidence whether SARS-CoV-2 can cause similar adverse outcomes.

\section{Perspectives on the severity of infection and other viruses}

What we do not yet know is how the severity of COVID-19 will impact on pregnancy (Dotters-Katz \& Hughes, 2020). In $8 \%$ of the 118 COVID-19 positive pregnant women, severe infection developed and the severity of disease increased in 6 women following delivery (Chen et al., $2020 \mathrm{~b}$ ). The majority of studies suggest careful monitoring of COVID-19 pregnancies with measures to prevent neonatal infection. There is a paradigm shift in the management of pregnant women during a pandemic whilst maintaining safety of patients and healthcare providers. Limited data on pregnant infected women suggests COVID-19 can have an association with higher risk of fetal respiratory distress and lung diseases. It would be beneficial to start analysing data comparing healthy pregnant women with women who have comorbidities and smoking status. The context of SARS-CoV-2 related pregnancies should be placed against Parvovirus B19, CMV, Rubella and VZV risks for which we have significant evidence base. The American Society for Reproductive Medicine (ASRM Task force) raises concerns regarding the usage and storage of gametes during this COVID-19 pandemic (Segars et al., 2020). Given the numbers of unknown asymptomatic pregnant women presenting in maternity units, clearly a high degree of clinical vigilance is required (Govind et al., 2020). On the other hand, where universal testing was undertaken in a cohort of 215 pregnant women, this revealed $13.5 \%$ who were asymptomatic, tested positive for RT-PCR SARS-CoV-2 (Sutton et al., 2020).

Interpreting virology test results remain overlooked in clinical and research settings (Sethuraman et al., 2020; Wölfel et al., 2020) while little attention has been made to factor in the humoral responses to SARS-CoV-2 (Cuo et al., 2020) as has been the incubation of the SARS-CoV-2 virus (Lauer et al., 2020; Zhao et al., 2020). Perhaps most striking is to note that the false negative RT-PCR is $100 \%$ on day 1 of the infectious period, declining to $67 \%$ on day 4 post symptoms onset (Kucirka et al., 2020), it is remarkable so many negative single RT-PCR reports dominate the field and especially on the non-peer reviewed MerRxiv platform without any controls now being reported in the media. Furthermore, numerous reports are now incorporated in a plethora of systemic analyses, sometimes duplicating the cases when published elsewhere. So many SARS-CoV-2 positive babies under 12 -24 hours are now known. Placing into context when RT-PCR becomes effectively positive and the incubation period, then there is a strong likelihood that the SARS-CoV-2 neonatal infection pre-existed the birth, and more careful and controlled studies will be required in future. Reports which reassure that is no SARS-CoV-2 viral presence in semen appear misleading as RT-PCR tests performed after a median of 31 days (interquartile range, 29-36 days) post infection (Pan et al., 2020; Eisenberg $M L, 2020)$ are likely to be negative anyway. The optimal RT-PCR testing is within the 6-12day period post infection (Guo et al., 2020; Kucirka et al., 2020; Lauer et al., 2020; Sethuraman et al., 2020).

\section{Conclusion}

Numerous reports suggest vertical transmission as a possibility and there is a likelihood of the infection being acquired peripartum. Factoring in SARS-CoV-2 virus incubation and diagnostics of when RT-PCR becomes positive may support vertical transmission in infected babies. However, more controlled data is required to decipher the underlying risks of maternal and fetal infections, possible vertical transmission and early pregnancy risk. Early pregnancy risks due to denuded oocytes and biopsied embryos need to be considered in IVF procedures given their potential susceptibility to SARS-CoV-2 infection. IUI provides a safer logistical early treatment option compared with multi-level complexities of IVF, offering reduced risks and non-surgical interventions. Maternal mortality rate of $5.6(95 \%$ CI 1.8-13.1) per 100,000 maternities or a case fatality of $1.2 \%(95 \%$ CI $0.4-2.7 \%)$ in the UK is recorded. It appears around $10 \%$ of SARS-CoV-2 infected pregnant women require hospitalisation with respiratory support, while $5 \%$ $(n=12)$ of infants tested positive for SARS-CoV-2 RNA, and half of these within 12 hours after birth. Co-morbidities are a major factor in SARS-CoV-2 infected pregnant women. Miscarriages, premature deliveries in the third trimester and neonatal infections are associated with SARS-CoV-2 infected pregnant women. As the science of diagnostics evolve information on optimal sampling and timing may confirm intrapartum vertical transmission from mother to baby which cannot be ruled out at this stage. Importantly, this limited information should be used to counsel and protect mothers and babies of the risks as well as protecting maternity and neonatal care teams from harm of SARSCoV-2 infection.

\section{Conflict of Interest}

The author has no conflict of interest to declare.

\section{Corresponding Author:}

Gulam Bahadur

Reproductive Medicine Unit, North Middlesex University Hospital

Old Admin Block, London, UK

E-mail: bahadur.g@gmail.com

\section{REFERENCES}

Alzamora MC, Paredes T, Caceres D, Webb CM, Valdez LM, La Rosa M. Severe COVID-19 during Pregnancy and Possible Vertical Transmission. Am J Perinatol. 2020.

PMID: 32305046 DOI: 10.1055/s-0040-1710050.

Bahadur G, Homburg R, Bosmans JE, Huirne JAF, Hinstridge $\mathrm{P}$, Jayaprakasan $\mathrm{K}$, Racich $\mathrm{P}$, Alam R, Karapanos I, Illahibuccus A, Al-Habib A, Jauniaux E. Observational retrospective study of UK national success, risks and costs for 319,105 IVF/ICSI and 30,669 IUI treatment cycles. BMJ Open. 2020;10:e034566. PMID: 32184314 DOI: 10.1136/bmjopen-2019-034566. 
Baud D, Greub G, Favre G, Gengler C, Jaton K, Dubruc E, Pomar L. Second-Trimester Miscarriage in a Pregnant Woman With SARS-CoV-2 Infection. JAMA. 2020:e207233 PMID: 32352491 DOI: 10.1001/jama.2020.7233

Chen $\mathrm{H}$, Guo J, Wang C, Luo F, Yu X, Zhang W, Li J, Zhao D, Xum D, Gong Q, Liao J, Yang H, Hou W, Zhang Y. Clinical characteristics and intrauterine vertical transmission potential of COVID-19 infection in nine pregnant women: a retrospective review of medical records. Lancet 2020;395: 809-15. PMID: 32151335 DOI: 10.1016/S01406736(20)30360-3.

Chen L, Li Q., Zheng D, Jiang H, Wei Y, Zou L, Feng L. Clinical Characteristics of Pregnant Women with Covid-19 in Wuhan, China. N Engl J Med. 2020:NEJMc2009226. PMID: 32302077 DOI: 10.1056/NEJMc2009226.

Cheruiyot I, Henry BM, Lippi G. Is there evidence of intra-uterine vertical transmission potential of COVID-19 infection in samples tested by quantitative RT-PCR? Eur J Obstet Gynecol. 2020: S0301-2115(20)30219-0. PMID: 32336661 DOI: $10.1016 /$ j.ejogrb.2020.04.034.

Colaco S, Chhabria K, Singh N, Bhide A, Singh D, Singh A, Husein A, Mishra A, Sharma R, Ashary N, Modi D. Expression of SARS-CoV-2 receptor ACE2 and the spike protein processing enzymes in developing human embryos. arXiv:2004.04935. 2020 Available at: https://arxiv.org/ abs/2004.04935

Dashraath $\mathrm{P}$, Wong JLJ, Lim MXK, Lim LM, Li S, Biswas A, Choolani M, Mattar C, Su LL. Coronavirus disease 2019 (COVID-19) pandemic and pregnancy. Am J Obstet Gynecol. 2020:S0002-9378(20)30343-4. PMID: 32217113. DOI: $10.1016 /$ j.ajog.2020.03.021.

Di Mascio D, Khalil A, Saccone G, Rizzo G, Buca D, Liberati M, Vecchiet J, Nappi L, Scambia G, Berghella V, D'Antonio F. Outcome of Coronavirus spectrum infections (SARS, MERS, COVID 1 -19) during pregnancy: a systematic review and meta-analysis. Am J Obstet Gynecol MFM. 2020:100107. PMID: 32292902 DOI: 10.1016/j.ajogmf.2020.100107

Dong L, Tian J, He S, Zhu C, Wang J, Liu C, Yang J. Possible vertical transmission of SARS-CoV-2 from an infected mother to her newborn. JAMA. 2020;323:1846-8 PMID: 32215581 DOI: $10.1001 /$ jama.2020.4621

Dotters-Katz SK, Hughes BL. Considerations for Obstetric Care during the COVID-19 Pandemic. Am J Perinatol. 2020. PMID: 32303077 DOI: 10.1055/s-0040-1710051.

Eisenberg ML., Coronavirus Disease 2019 (COVID-19) and men's reproductive health. Fertil Steril.2020; 113: 1154 DOI: $10.1016 /$ j.fertnstert.2020.04.039

Favre G, Pomar L, Musso D, Baud D. 2019-nCoV epidemic: what about pregnancies? Lancet. 2020; 395:e40. PMID: 32035511 DOI:10.1016/S0140-6736(20)30311-1

Fornari F. Vertical Transmission of Covid-19-A Systematic Review. J Pediatr Perinatol Child Health. 2020; 4: 007-013 DOI: $10.26502 /$ jppch.7405034

Goldsmith C S, Miller SE, Martines RB, Bullock HA, Zaki SR. Electron microscopy of SARS-CoV-2: a challenging task. Lancet. 2020. PMID: 32442529 DOI: 10.1016/S01406736(20)31188-0.
Govind A, Essien S, Karthikeyan A, Fakokunde A, Janga D, Yoong W, Nakhosteen A, Novel Coronavirus COVID-19 in late pregnancy: Outcomes of first nine cases in an inner-city London Hospital. Eur J Obstet Gynecol. 2020: S0301-2115(20)30257-8 PMID: 32402627 DOI: 10.1016/j.ejogrb.2020.05.004

Guo L, Ren L, Yang S, Xiao M, Chang D, Yang F, Dela Cruz CS, Wang $Y$, Wu C, Xiao $Y$, Zhang L, Han L, Dang S, Xu Y, Yang Q, Xu S, Zhu H, Xu Y, Jin Q, Sharma L, Wang L, Wang J. Profiling Early Humoral Response to Diagnose Novel Coronavirus Disease (COVID-19). Clin Infect Dis. 2020:ciaa310. PMID: 32198501 DOI: 10.1093/cid/ ciaa310.

Hosier H, Farhadian SF, Morotti RA, Deshmukh U, Lu-Culligan A, Campbell KH, Yasumoto $Y$, Vogels CB, Casanovas-Massana $A$, Vijayakumar $P$, Geng $B$, Odio $C D$, Fournier J, Brito AF, Fauver JR, Liu F, Alpert T, Tal R, Szigeti-Buck K, Perincheri S, Larsen $C P$, et al. SARS-CoV-2 infection of the placenta. J Clin Invest. 2020:139569. PMID: 32573498. DOI: $10.1172 /$ JCI139569.

Hu X, Gao J, Luo X, Feng L, Liu W, Chen J, Benachi A, De Luca D, Chen L. Severe Acute Respiratory Syndrome Coronavirus 2 (SARS-CoV-2) Vertical Transmission in $\mathrm{Ne}-$ onates Born to Mothers With Coronavirus Disease 2019 (COVID-19) Pneumonia. Obstet Gynecol. 2020:10.1097/ AOG.0000000000003926. PMID: 32332320 DOI: 10.1097/ AOG.0000000000003926.

Karami P, Naghavi M, Feyzi A, Aghamohammadi M, Novin MS, Mobaien A, Qorbanisani M, Karami A, Norooznezhad AH. Mortality of a pregnant patient diagnosed with COVID-19: A case report with clinical, radiological, and histopathological findings. Travel Med Infect Dis. 2020:101665. PMID: 32283217 DOI: $10.1016 /$ j.tmaid.2020.101665.

Karimi-Zarchi $M$, Neamatzadeh $H$, Dastgheib SA, Abbasi $H$, Mirjalili SR, Behforouz A, Ferdosian F, Bahrami R. Vertical Transmission of Coronavirus Disease 19 (COVID-19) from Infected Pregnant Mothers to Neonates: A Review. Fetal Pediatr Pathol. 2020:1-5. PMID: 32238084 DOI: 10.1080/15513815.2020.1747120.

Kelly JC, Dombrowksi M, O'neil-Callahan M, Kernberg AS, Frolova AI, Stout MJ. False-Negative COVID-19 Testing: Considerations in Obstetrical Care. Am J Obstet Gynecol MFM. 2020: 100130. PMID: 32346672 DOI: 10.1016/j. ajogmf.2020.100130.

Khan S, Peng L, Siddique R, Nabi G, Nawsherwan, Xue M, Liu J, Han G. Impact of COVID-19 infection on pregnancy outcomes and the risk of maternal-to-neonatal intrapartum transmission of COVID-19 during natural birth. Infect Control Hosp Epidemiol. 2020; 4: 748-50. PMID: 32279693 DOI: $10.1017 /$ ice.2020.84.

Kimberlin DW, Stagno S. Can SARS-CoV-2 infection be acquired in utero?: More definitive evidence is needed. JAMA. 2020. PMID: 32215579 DOI: 10.1001/jama.2020.4868.

Kirtsman M, Diambomba Y, Poutanen SM, Malinowski AK, Vlachodimitropoulou E, Parks WT, Erdman L, Morris SK, Shah PS. Probable congenital SARS-CoV-2 infection in a neonate born to a woman with active SARS-CoV-2 infection. CMAJ. 2020; 192:E647-E50. PMID: 32409520. DOI: 10.1503/cmaj. 200821. 
Knight M, Bunch K, Vousden N, Morris E, Simpson N, Gale C, O'Brien P, Quigley M, Brocklehurst P, Kurinczuk JJ. Characteristics and outcomes of pregnant women hospitalised with confirmed SARS-CoV-2 infection in the UK: a national cohort study using the UK Obstetric Surveillance System (UKOSS). MedRxiv. 2020 DOI:10.1101/2020.05.08.20089268.

Kucirka LM, Lauer SA, Laeyendecker O, Boon D, Lessler J. Variation in False-Negative Rate of Reverse Transcriptase Polymerase Chain Reaction-Based SARS-CoV-2 Tests by Time Since Exposure. Ann Intern Med. 2020:M20-1495. PMID: 32422057 DOI: $10.7326 /$ M20-1495. Epub ahead of print.

Lauer SA, Grantz KH, Bi Q, Jones FK, Zheng Q, Meredith HR, Azman AS, Reich NG, Lessler J. The Incubation Period of Coronavirus Disease 2019 (COVID-19) From Publicly Reported Confirmed Cases: Estimation and Application. Ann Intern Med. 2020; 172:577-82. PMID: 32150748 DOI: 10.7326/M20-0504.

Li M, Chen L, Zhang J, Xiong C, Li X. The SARS-CoV-2 receptor ACE2 expression of maternal-fetal interface and fetal organs by single-cell transcriptome study. PLoS One 15:e0230295. 2020. PMID: 32298273 DOI: 10.1371/ journal.pone.0230295.

Monteleone PA, Nakano M, Lazar V, Gomes AP, de H Martin, Bonetti TC. A review of initial data on pregnancy during the COVID-19 outbreak: implications for assisted reproductive treatments. JBRA Assist Reprod. 2020;24:219-25

Moreno I, Codoñer FM, Vilella F, Valbuena D, Martinez-Blanch JF, Jimenez-Almazán J, Alonso R, Alamá $P$, Remohí J, Pellicer A, Ramon D, Simon C. Evidence that the endometrial microbiota has an effect on implantation success or failure. Am J Obstet Gynecol. 2016; 215:684-703 PMID: 27717732 DOI: 10.1016/j.ajog.2016.09.075

ONS -Office of National Statistics (UK) COVID-19 deaths of pregnant and perinatal women. 2020. Available at: https://www.ons.gov.uk/aboutus/transparencyandgovernance/freedomofinformationfoi/covid19deathsofpregnantandperinatalwomen

Pan F, Xiao X, Guo J, Song Y, Li H, Patel DP, Spivak AM, Alukal JP, Zhang $X$, Xiong $C$, Li PS, Hotaling JM. No evidence of severe acute respiratory syndrome-coronavirus 2 in semen of males recovering from coronavirus disease 2019. Fertil Steril. 2020;113:1135-9. PMID: 32482249. DOI: $10.1016 /$ j.fertnstert.2020.04.024.

Parazzini F, Bortolus R, Mauri PA, Favilli A, Gerli S, Ferrazzi $E$. Delivery in pregnant women infected with SARSCoV-2: A fast review. Int J Gynaecol Obstet. 2020. PMID: 32271947 DOI: 10.1002/ijgo.13166.

Penfield CA, Brubaker SG, Limaye MA, Lighter J, Ratner AJ, Thomas KM, Meyer J, Roman AS. Detection of SARSCOV-2 in Placental and Fetal Membrane Samples. Am J Obstet Gynecol MFM. 2020:100133. PMID: 32391518 DOI: 10.1016/j.ajogmf.2020.100133.

Pereira VM, Reis FM, Santos RA, Cassali GD, Santos SH, Honorato-Sampaio K, dos Reis AM. Gonadotropin stimulation increases the expression of angiotensin-(1--7) and MAS receptor in the rat ovary. Reprod Sci. 2009; 16:116574. PMID: 19703990 DOI: 10.1177/1933719109343309.
Schwartz DA, Dhaliwal A. Infections in pregnancy with Covid-19 and other respiratory RNA virus diseases are rarely, if ever, transmitted to the fetus: experiences with coronaviruses, HPIV, hMPV RSV, and Influenza. Arch Pathol Lab Med. 2020. PMID: 32338533. DOI: 10.5858/arpa.2020-0211-SA.

Segars J, Katler Q, McQueen DB, Kotlyar A, Glenn T, Knight Z, Feinberg EC, Taylor HS, Toner JP, Kawwass JF, for the ASRM Coronavirus/COVID-19 Task Force. Fertil Steril. 2020. DOI: $10.1016 /$ j.fertnstert.2020.04.025

Sethuraman N, Jeremiah SS, Ryo A. Interpreting Diagnostic Tests for SARS-CoV-2. JAMA. 2020. PMID: 32374370 DOI: $10.1001 /$ jama.2020.8259.

Shanes ED, Mithal LB, Otero S, Azad HA, Miller ES, Goldstein JA. Placental Pathology in COVID-19. Am J Clin Pathol. 2020: aqaa089. PMID: 32441303 DOI: 10.1093/ ajcp/aqaa089

Silasi M, Cardenas I, Racicot K, Kwon JY, Aldo P, Mor G. Viral infections during pregnancy Am J Reprod Immunol. 2015; 73: 199-213. PMID: 25582523 DOI: 10.1111/ aji.12355.

Stanley KE, Thomas E, Leaver M, Wells D. Coronavirus disease (COVID-19) and fertility: viral host entry protein expression in male and female reproductive tissues. Fertil Steril, 2020. DOI: https://doi.org/10.1016/j.fertnstert.2020.05.001

Sutton D, Fuchs K, D'Alton M, Goffman D. Universal Screening for SARS-CoV-2 in Women Admitted for Delivery. N Engl J Med. 2020;382:2163-4. PMID: 32283004 DOI: $10.1056 /$ NEJMc2009316.

Vaz-Silva J, Carneiro MM, Ferreira MC, Pinheiro SV, Silva $D A$, Silva-Filho AL, Witz CA, Reis $A M$, Santos $R A$, Reis FM. The vasoactive peptide angiotensin-(1-7), its receptor Mas and the angiotensin-converting enzyme type 2 are expressed in the human endometrium. Reprod Sci. 2009;16:247-56. PMID: 19164480 DOI: $10.1177 / 1933719108327593$.

Venceslau EM, Guida JPS, Nobrega GdM, Samogim AP, Parise $\mathrm{PL}$, Japecanga RR, Toledo-Teixeira DAd, Forato J, Antolini-Tavares A, Souza A, Altemani A, Consonni SR, Passini R Jr, Amaral E, Proenca-Modena JL, Costa ML ; The Zika-Unicamp Network. Adequate Placental Sampling for the Diagnosis and Characterization of Placental Infection by Zika Virus Front. 2020. PMID: 32153521 DOI: 10.3389/ fmicb.2020.00112

Wang S, Guo L, Chen L, Liu W, Cao Y, Zhang J, Feng L. A case report of neonatal COVID-19 infection in China. Clin Infect Dis. 2020:ciaa225. PMID: 32161941 DOI: 10.1093/cid/ciaa225.

Wölfel R, Corman VM, Guggemos W, Seilmaier M, Zange S, Müller MA, Niemeyer D, Jones TC, Vollmar P, Rothe C, Hoelscher M, Bleicker T, Brünink S, Schneider J, Ehmann R, Zwirglmaier K, Drosten C, Wendtner C. Virological assessment of hospitalized patients with COVID-2019. Nature. 2020; 581:465-9. PMID: 32235945. DOI: 10.1038/ s41586-020-2196-x. 
Wong SF, Chow KM, Leung TN, Ng WF, Ng TK, Shek CC, Ng PC, Lam PW, Ho LC, To WW, Lai ST, Yan WW, Tan PY. Pregnancy and perinatal outcomes of women with severe acute respiratory syndrome. Am J Obstet Gynecol. 2004; 191: 292-7. PMID: 15295381 DOI: $10.1016 / \mathrm{j}$. ajog.2003.11.019.

Xiong X, Wei H, Zhang Z, Chang J, Ma X, Gao X, Chen Q, Pang Q. Vaginal Delivery Report of a Healthy Neonate Born to a Convalescent Mother with COVID-19. J Med Virol. 2020. PMID: 32275072 DOI: $10.1002 / j m v .25857$

Yang Z, Wang M, Zhu Z, Liu Y. Coronavirus disease 2019 (COVID-19) and pregnancy: a systematic review. J Mater Fetal Neonatal Med. 2020; 1-4. PMID: 32354293. DOI: $10.1080 / 14767058.2020 .1759541$.

Yates L, Pierce M, Stephens $S$, Mill AC, Spark $P$, Kurinczuk JJ, Valappil M, Brocklehurst P, Thomas SH, Knight M. Influenza $\mathrm{A} / \mathrm{H} 1 \mathrm{~N} 1 \mathrm{v}$ in pregnancy: an investigation of the characteristics and management of affected women and the relationship to pregnancy outcomes for mother and infant. Health Technol Assess. 2010; 14:109-82. PMID: 20630123. DOI: 10.3310/hta14340-02.

Yu N, Li W, Kang Q, Xiong Z, Wang S, Lin X, Liu Y, Xiao J, Liu $H$, Deng $D$, Chen $S$, Zeng $W$, Feng $L$, Wu J. Clinical features and obstetric and neonatal outcomes of pregnant patients with COVID-19 in Wuhan, China: a retrospective, single-centre, descriptive study. Lancet Infect Dis. 2020:pii: S1473-3099(20)30176-6. PMID: 32220284 DOI: 10.1016/S1473-3099(20)30176-6
Zaigham M, Andersson O. Maternal and Perinatal Outcomes with COVID-19: a systematic review of 108 pregnancies. Acta Obstet Gynecol Scand. 2020. PMID: 32259279 DOI: 10.1111/aogs.13867

Zamaniyan M, Ebadi A, Aghajanpoor SM, Rahmani Z, Haghshenas M, Azizi S. Preterm delivery in pregnant woman with critical COVID-19 pneumonia and vertical transmission, Prenatal diagnosis. 2020. PMID: 32304114 DOI: $10.1002 /$ pd. 5713

Zhao J, Yuan Q, Wang H, Liu W, Liao X, Su Y, Wang X, Yuan J, Li T, Li J, Qian S, Hong C, Wang F, Liu Y, Wang Z, He Q, Li Z, He B, Zhang T, Fu Y, et al. Antibody responses to SARS-CoV-2 in patients of novel coronavirus disease 2019. Clin Infect Dis. 2020:ciaa344. PMID: 32221519 DOI: 10.1093/cid/ciaa344.

Zeng L, Xia S, Yuan W, Yan K, Xiao F, Shao J, Zhou W. Neonatal early-onset infection with SARS-CoV-2 in 33 neonates born to mothers with COVID-19 in Wuhan, China. JAMA Pediatr 2020a: e200878. PMID: 32215598 DOI: 10.1001/jamapediatrics. 2020.0878

Zeng $\mathrm{H}$, Xu C, Fan J, Tang Y, Deng Q, Zhang W, Long X. Antibodies in Infants Born to Mothers With COVID-19 Pneumonia. JAMA. 2020b; 323:1848-9 PMID: 32215589 DOI: $10.1001 /$ jama.2020.4861.

Zhu H, Wang L, Fang C, Peng S, Zhang L, Chang G, Zia $\mathrm{S}$, Zhou W. Clinical analysis of 10 neonates born to mothers with 2019- nCoV pneumonia. Transl Pediatr 2020; 9: 51-60. PMID: 32154135 DOI: $10.21037 /$ tp.2020.02.06 